\title{
A VARIAÇÃO LINGUÍSTICA NA EDUCAÇÃO CONTEMPORÂNEA: concepções e práticas pedagógicas
}

\author{
Maria Eduarda dos Santos Chaibel \\ Ediene Pena Ferreira ${ }^{2}$
}

\section{Resumo}

O objetivo desta pesquisa em educação e linguagem consiste em compreender o que a Linguística brasileira diz ser tratar a variação linguística no ensino de Língua Portuguesa. Estudiosos têm divulgado reflexões e propostas para um ensino que considere os pressupostos teóricos em torno da variação linguística. Entretanto, ainda é frequente a crítica de linguistas quanto à dificuldade de articulação entre o desenvolvimento da teoria e a atividade de ensino no ambiente escolar. Percebemos nisso a necessidade de uma investigação que evidencie o que os estudos linguísticos dizem ser variação e qual a orientação da Linguística para a articulação da variação com o ensino. Para essa investigação, selecionamos pesquisas de doutores e especialistas da área, autores de textos publicados em livros, teses, dissertações e artigos publicados em meios acadêmicos/ educacionais oficiais, principalmente nos últimos 20 anos, período de divulgação deste tema nas diretrizes oficiais de ensino. Nas pesquisas analisadas, apesar de ainda observarmos contradições, dificuldades de compreensão quanto à concepção de língua e falta de consenso terminológico entre os linguistas, os pesquisadores orientam que o ensino deve partir da reflexão e do acesso dos alunos às variedades da língua como legítimas, de forma a combater o preconceito linguístico, e lhes oferecer possibilidades de escolhas, por meio do reconhecimento das normas efetivamente praticadas pelos falantes da língua portuguesa.

Palavras-chave: Educação. Variação Linguística. Ensino.

\section{LINGUISTIC VARIATION IN CONTEMPORARY EDUCATION: pedagogical conceptions and practices}

\begin{abstract}
The purpose of this research in education and language is to understand linguistic variation in Portuguese language teaching as conceived by Brazilian linguistics.

\footnotetext{
1 Mestre em Educação - Universidade Federal do Oeste do Pará. E-mail: duda.chaibe@gmail.com

2 Doutora em Linguística. Professora do Instituto de Ciências da Educação da Universidade Federal do Oeste do Pará. E-mail: ediene.ferreira@ufopa.edu.br
} 
Scholars have disseminated reflections and proposals for a teaching that considers the theoretical assumptions involving linguistic variation. However, the criticism of linguists about the difficulty of articulation between the development of theory and the activity of teaching in the school environment is still frequent. This leads us to the necessity of an investigation that evidences the concept of variation established by linguistic studies and the suggestions of Linguistics on the articulation of variation and teaching. For this investigation, we selected studies from doctors and specialists in the field, authors of texts published in books, theses, dissertations and articles published in academic/educational official database, mainly in the last 20 years, period of dissemination of this topic in official teaching guidelines. In the studies that were analyzed, although we still see contradictions, difficulties in understanding the conception of language and lack of terminological consensus among linguists, the researchers point out that teaching must start from the reflection and the students' access to the varieties of language as legitimate, as a way to combat linguistic prejudice, and to offer them possibilities of choices by means of the recognition of the norms effectively practiced by the speakers of the Portuguese language.

Keywords: Education. Linguistic Variation. Teaching.

\section{LA VARIACIÓN LINGÜÍSTICA EN LA EDUCACIÓN CONTEMPORÁNEA: concepciones y prácticas pedagógicas}

\section{Resumen}

El objetivo de esta investigación en educación y lenguaje consiste en comprender lo que la lingüística brasileña dice tratar la variación lingüística en la enseñanza de lengua portuguesa. Estudiantes han divulgado reflexiones y propuestas para una enseñanza que considere los presupuestos teóricos en torno a la variación lingüística. Sin embargo, aún es frecuente la crítica de lingüistas en cuanto a la dificultad de articulación entre el desarrollo de la teoría y la actividad de enseñanza en el ambiente escolar. Se percibe en ello la necesidad de una investigación que evidencie lo que los estudios lingüísticos dicen ser variación y cuál es la orientación de la Lingüística para la articulación de la variación con la enseñanza. Para esa investigación, seleccionamos investigaciones de doctores y especialistas del área, autores de textos publicados en libros, tesis, disertaciones y artículos publicados en medios académicos / educativos oficiales, principalmente en los últimos 20 años, período de divulgación de este tema en las directrices oficiales de enseñanza. En las investigaciones analizadas, aunque todavía observamos contradicciones, dificultades de comprensión en cuanto a la concepción de lengua y falta de consenso terminológico entre los lingüistas, los investigadores orientan que la enseñanza debe partir de la reflexión y del acceso de los alumnos a las variedades de la lengua como legítimas, para combatir el prejuicio lingüístico, y ofrecerles posibilidades de elección, por medio del reconocimiento de las normas efectivamente practicadas por los hablantes de la lengua portuguesa.

Palabras clave: Educación. Variación lingüística. Enseñanza. 


\section{INTRODUÇÃO}

Desenvolver uma pesquisa em educação implica não só considerar o ato de educar, mas, também, pensar no desenvolvimento da sociedade. Trata-se de uma área que compreende uma multiplicidade de problemas, uma variedade de abordagens que pode envolver observações de sala de aula, bibliotecas, comunidades ou pode compreender a pesquisa sistemática documentada sobre questões teóricas ou conceituais. É neste último tipo de pesquisa que se enquadra este trabalho, pois analisar um problema teórico / conceitual, nessa área, é buscar compreender o problema que gira em torno do objeto de um determinado processo pedagógico. Se há a intenção de intervir na educação, de buscar novas propostas para o ensino, é preciso conhecer o objeto, compreender como funciona, como se define, para pensar o ensino, a educação.

O objetivo desta pesquisa em educação e linguagem consiste em discutir o conceito de um dos eixos do ensino e como se compreende este para o processo pedagógico, pois, para entender os processos educacionais, é preciso compreender seus objetos. De modo mais específico, o objetivo é compreender o que a Linguística brasileira diz ser tratar a variação linguística no ensino de língua portuguesa.

Embora a relação Linguística e Ensino não seja direta, os estudos linguísticos e suas diferentes concepções de língua e de gramática apresentam impacto sobre o ensino de línguas, que se mostra pautado na forte concepção de "certo e errado", na língua como fenômeno homogêneo, ensinada apenas como sinônimo de um conjunto de normas descritas na gramática tradicional e demais instrumentos normativos.

Estudiosos têm escrito, orientado e divulgado pesquisas para o ensino não mais baseado apenas nos preceitos da Gramática Tradicional, mas na reflexão sobre o real uso da língua, sobre as regras que permitem seu funcionamento, que estudem a língua em sua interação social, que estimule o ensino em uma direção positiva de todas as variedades. 
Apesar da divulgação de novas discussões, e das críticas em torno das concepções tradicionais de gramática, é frequente a crítica de linguistas dessas produções quanto à dificuldade de articulação entre o desenvolvimento da teoria e a atividade de ensino escolar (BORTONIRICARDO, 2004; SUASSUNA, 1995; SCHERRE, 2005; ANTUNES, 2007; BAGNO, 2007; FARACO, 2008; NEVES, 2014). Muitos são os problemas enumerados para tal dificuldade 3 , dentre eles, destacamos a falta de compreensão sobre o objeto da prática pedagógica e o peso da normatividade que rege as relações sociais e, consequentemente, o ensino de língua portuguesa. Compartilhando as palavras de Callou (2008), apesar das contribuições recentes da Linguística para o ensino, a política educacional pouco mudou, há apenas indícios de mudança.

O problema que impulsiona o desenvolvimento desta pesquisa é, portanto, o seguinte: como a Linguística compreende articular a variação ao ensino de Língua Portuguesa?

Temos como objetivo geral: investigar como as pesquisas linguísticas orientam a articulação da variação linguística com o ensino de língua. $E$ como objetivos específicos:

- Caracterizar o ideário do ensino de Língua Portuguesa na contemporaneidade.

- Discutir o que a Linguística diz ser articular a variação linguística ao ensino de Língua Portuguesa.

- Examinar se há consenso entre os linguistas nas reflexões em torno de concepções e práticas pedagógicas que consideram a variação linguística: se deve ser mais um tópico nos planos curriculares, se inclui o ensino de gramática, se variação e gramática são relacionáveis.

3 Problemas relacionados, principalmente, ao descaso quanto às políticas públicas educacionais, quanto às gritantes diferenças entre classes sociais, o que dificulta o acesso democrático ao ensino de qualidade; quanto à deficiente formação de professores, seja pela desvalorização da profissão docente, pela insuficiência de carga horária nas disciplinas do curso, pela falta de compreensão teórica, e assim pela insegurança em mudar suas práticas tradicionais. 
Consideramos, para essa investigação, pesquisas de doutores e especialistas da área, autores de textos publicados em meios acadêmicos/ educacionais oficiais, principalmente nos últimos 20 anos, período de divulgação deste tema nas diretrizes oficiais de ensino.

Para a análise das abordagens da produção intelectual sobre a variação linguística, esta pesquisa bibliográfica, caracteriza-se como conceitual/ teórica e parte do levantamento bibliográfico dos linguistas brasileiros e das obras que tratam do fenômeno da variação.

A pesquisa partiu, primeiramente, da localização das pesquisas linguísticas, considerando critérios de identificação e seleção. Na primeira seleção, os textos que constituem o corpus inicial seguiram os seguintes critérios: publicação em congresso da Linguística brasileira e internacional, títulos referentes à variação, gramática e ensino de língua, disponíveis em anais a partir dos últimos 20 anos, período que neste trabalho é um dos critérios de seleção por não se pretender abranger toda a grande produção existente, por ser um período de maior destaque para os estudos linguísticos e o ensino de língua portuguesa já que "a entrada dos linguistas brasileiros nos debates sobre o ensino se deu intensamente na década de 1980" (FARACO, 2008, p. 189), período também de divulgação das orientações dos PCN.

Para a constituição do corpus de textos acadêmicos/científicos nesta primeira seleção, investigamos os seguintes anais de Congresso da Linguística Nacionais e Internacionais, considerados os principais eventos da área de Linguagem, Educação e Ensino de Língua: Associação Brasileira de Linguística (ABRALIN), Simpósio Mundial de Estudos de Língua Portuguesa (SIMELP), Associação Nacional de Pós-Graduação e Pesquisa em Letras e Linguística (ANPOLL), Associação Portuguesa de Linguística (APL) e Congresso Internacional de Dialetologia e Sociolinguística (CIDS). Contabilizamos, com essa investigação nos anais disponíveis em cada site um total de, 29 textos que discutem variação, gramática e ensino de língua: 4 textos nos anais do SIMELP, do ano de 2013; 2 textos nos anais do CIDS do 
ano e 2012; 18 textos nos anais de ABRALIN dos anos de 2005, 2007 e 2011; 3 textos dos anais da ANPOLL dos anos de 2006, 2010 e 2015; 2 textos dos anais da APL do ano de 2007.

Para uma investigação mais abrangente, vimos a necessidade de uma segunda seleção para constituir um corpus a partir da ferramenta de busca do google acadêmico, onde é possível encontrar textos em maior quantidade e de fácil acesso, com o uso dos seguintes unitermos/palavraschaves ou frases: variação linguística e ensino de língua, o que é ensinar variação, língua e variação; que nos apresentou uma quantidade maior de pesquisas. Nesta segunda seleção, consideramos os seguintes critérios: publicação em bibliotecas eletrônicas de universidades, em revistas qualificadas, em outros eventos acadêmico-científicos, textos que objetivam discutir variação, gramática e ensino de língua, textos publicados nos últimos 20 anos.

Com a seleção de artigos, teses e dissertações, investigamos, nos textos selecionados, textos de especialistas citados como referências que tem como objetivo básico discutir os avanços da Linguística em articulação com o ensino - o que identificamos explícita ou implicitamente nos títulos das obras - e, diante disso, recorremos a tais fontes para constituir o corpus principal - livros e capítulos de livros - a partir dos quais desenvolvemos nossa investigação. Nosso objetivo não é abranger todos os trabalhos ou apresentar panorama exaustivo, mas sistematizar resultados que possam oferecer uma visão geral.

Podemos dizer que tais especialistas/pesquisadores/linguistas brasileiros, fontes utilizadas nos textos da primeira e segunda seleção, são referências no tema em questão, linguistas, sociolinguistas e estudiosos da língua e, portanto, constituem o corpus principal de análise, já que apresentam livros ou artigos publicados em livros, fontes primárias das informações que analisamos nos textos encontrados nas demais fontes.

Elencamos os especialistas cujos trabalhos constituem o corpus selecionado para a investigação do nosso problema de pesquisa: Carlos 
Faraco, Marcos Bagno, Maria Helena de Moura Neves, Stella Bortoni-Ricardo, Silvia Rodrigues Vieira, Silvia Brandão, Irandé Antunes, Izete Coelho, Rosa Mattos e Silva, Lívia Suassuna, Ana Maria Zilles, Rosineide Sousa, Veruska Machado, Caroline Cardoso, Paula Cobucci, Vera Lucas Freitas, Maria Alice Tavares, Lucia Cyranka, Dinah Callou, Marco Antonio Martins, Juliene Lopes Pedrosa, Gilson Costa Freire, César Augusto Gozález, Luciene Simões, Simone Soares, Célia Regina Lopes.

Para a investigação do problema da pesquisa, fizemos a leitura das obras de modo a averiguar tanto os textos que traziam em seus títulos e resumos explicitamente o objetivo de discutir orientações para a prática pedagógica do ensino, conforme as pesquisas linguistas que explicitam a heterogeneidade da língua; quanto os textos que implicitamente, ao tratar sobre a necessidade de revisão nos conceitos relacionados ao ensino de língua, expõem orientações para o ensino considerando a variação. Para melhor explicitação, destacamos a transcrição de trechos das obras linguísticas que consideramos ser "respostas", ou indícios de resposta, para o problema desta pesquisa: o que a Linguística diz ser articular a variação linguística na prática pedagógica de ensino de Língua Portuguesa?

\section{DEBATES EM TORNO DA EDUCAÇÃO LINGUÍSTICA CONTEMPORÂNEA}

A educação escolar apresenta-se caracterizada pela tendência a reproduzir as relações de dominação da sociedade capitalista, o que, conforme afirmam Saviani e Duarte (2010), é possível superar, já que a ciência, a tecnologia, a técnica e a própria cultura são mediações produzidas pelo trabalho na relação entre os seres humanos e os meios de vida, que não são neutras, mas se constituem em forças de dominação e alienação e podem se constituir em elementos de emancipação humana. Frigotto (2006) aborda o quanto ainda há dificuldades a serem superadas para que projetos de educação possam alcançar o objetivo da formação, da promoção humana, formar sujeitos emancipados e superar a lógica do adestramento, para transformar a situação vigente, que, segundo ele, é 
difícil de ser transformada. Considerando um mundo com tanta miséria, o desenvolvimento científico não conduz, necessariamente, à emancipação. O que se tem é um modelo pedagógico que, ao buscar a integração entre teoria e prática, apresenta, nas palavras de Abrantes e Martins (2007), um realismo ingênuo e um pragmatismo subjetivista:

Privilegia-se $o$ conhecimento imediato em detrimento do conhecimento por conceitos [...]. Se por um lado, os conceitos se distanciam dos objetos, por outro não há nada mais apto para se aproximar de sua essencialidade, uma vez que o verdadeiro conhecimento não nos é dado pelo contato imediato (ABRANTES e MARTINS, 2007, p. 317).

Segundo os autores, o conhecimento é fruto da história humana, o indivíduo não produz, mas incorpora o conhecimento e, portanto, este precisa ser apreendido de forma sistemática, faz-se necessário conhecer o já produzido, conhecer o que se tem além do pragmático, do imediato.

Saviani (2003), ao discutir sobre o problema da subjetividade em Marx, defende, também, que cabe considerar a compreensão de que os homens determinam as circunstâncias ao mesmo tempo em que são determinados por ela. Temos, então, a concepção de subjetividade em que o homem se faz na história; o indivíduo só pode se constituir como homem e como sujeito de seus atos nas relações cotidianas com os outros homens, é histórico e social.

Nessa concepção, trabalho apresenta-se como atividade vital e como alienação, ao mesmo tempo em que o homem precisa agir sobre a natureza ajustando-a as suas necessidades, dessa forma produzindo a si mesmo, transcendendo como ser da natureza e constituindo-se como ser social, torna-se alienado pelo próprio trabalho; a busca do homem para satisfazer suas necessidades tem ocorrido de forma limitada, pois não supera a sociedade de classes que é fonte da apropriação do mais-valia (SAVIANI e DUARTE, 2010; SAVIANI, 2003; FRIGOTTO, 2006).

Com a manutenção da divisão de classes e da concentração de renda nas mãos de poucos, a educação escolar e as formações técnicas- 
profissionais mantêm-se precárias, longe de superar as desigualdades. Frigotto (2006) lembra que, mesmo com a Constituição Federal de 1988, com as Diretrizes Curriculares Nacionais, o analfabetismo continua alto, não há investimentos suficientes no ensino básico e no ensino superior, ênfase apenas para o trabalho simples, sem preocupação com a produção técnica, científica e tecnológica.

$\mathrm{Na}$ luta pela superação das desigualdades e do adestramento ao modelo capitalista, Frigotto (2006) destaca que muitos projetos são desenvolvidos, especialmente a partir da década de 1980, quando debates em congressos nacionais trazem a concepção de educação ominilateral e politécnica, que articule ciência, filosofia, trabalho, cultura e vida, teoria e prática, formação intelectual e produção material, no desenvolvimento dos fundamentos gerais de todo o processo de produção. Para superar as desigualdades e tornar o homem ser capaz de se incorporar em sua subjetividade e retrabalhar em seu meio as produções das gerações anteriores é necessário garantir ao indivíduo a educação escolar, formação profissional com bases mais complexas; o indivíduo precisa ser educado. (SAVIANI, 2003; FRIGOTTO, 2006, SAVIANI e DUARTE, 2010).

Nesse sentido, Frigotto (2006) destaca um desafio para um projeto de desenvolvimento nacional popular e democrático de massa no Brasil, que estabeleça a relação entre teoria e prática e a atuação na sociedade como sujeitos emancipados, esse desafio implica no enorme esforço de investimento em ciência, educação, tecnologia e infraestrutura, e o reconhecimento, pela sociedade, da educação como um problema, pois nunca se apresentou como problema para a classe dominante.

É por meio da educação com sentido emancipatório que parece haver a possibilidade de superar o adestramento ao sistema capitalista e desenvolver uma sociedade democrática. Adorno (2000), ao afirmar que só há democracia se houver uma sociedade de emancipados, explicita que educação não pode ser mera transmissão de conteúdos, mas utilizando-se do conceito de experiência formativa, defende que é preciso conferir 
sentido à história reelaborando a relação do passado ao presente, justamente para apreender o presente como sendo histórico, acessível a uma práxis transformadora. Não se esgotaria a experiência formativa no conteúdo formal, mas na superação de limites, do imediato, da fragmentação.

O sentido da escola está, portanto, em ampliar a possibilidade de apropriação das objetivações duradouras da humanidade, é possibilitar a superação da realidade imediata do aluno, alcançar o genérico-humano, o que pressupõe a educação escolar que proporcione ao aluno a apropriação do patrimônio intelectual da humanidade, conforme, também, verificamos em Frigotto (2006), Saviani (2003), Kuenzer (2003) que destacam a importância da relação entre conhecimento tácito e conhecimento científico, entre a teoria e prática, entre a formação intelectual e produção material, conceitos que se relacionam às categorias de Heller (2004).

O debate em torno do sentido da educação escolar deixa claro que a escola é importante para o desenvolvimento das capacidades do pensamento, que deve ter como objetivo orientar os educandos a um desconhecido que se necessita conhecer, levá-los a se apropriar de questões filosóficas e científicas para que tenha consciência do seu tempo histórico, suas possibilidades e seus limites e permitir-Ihes intervir na realidade, o que será bem mais sucedido quanto mais domínios conceituais tiver a sua disposição. O pensamento teórico se caracteriza como consciência histórica do movimento da humanidade do qual os indivíduos necessitam se apropriar: "Tais apropriações, por sua vez, não ocorrem espontaneamente, mas sim por meio dos processos educativos planejados para esse fim". (ABRANTES E MARTINS, 2007, p. 320).

A educação escolar faz sentido quando orienta para o domínio dos conhecimentos científicos, tecnológicos e sócio-históricos, e o que ainda temos é um modelo de escola para o cotidiano e não para o genérico humano. A partir dos estudiosos aqui colocados, priorizar o desenvolvimento de competências como capacidade de realizar tarefas práticas é deixar o 
indivíduo mais propenso à alienação, excluídos da participação do seu processo histórico.

Ressaltamos que não significa o retorno ao ensino tradicional, enciclopédico, ou transmissão de conteúdo como verdades absolutas, mas da necessidade de fundamentar a prática na reflexão-ação, dialogando o conhecimento sistemático, científico, global com o agir em sociedade.

Kuenzer (2003), Abrantes e Martins (2007), Frigotto (2006), Duarte (2006), Heller (2004), Saviani (2003), Saviani e Duarte (2010), Adorno (2000) são apenas alguns dos estudiosos que discutem a importância de se pensar 0 sujeito como resultado da produção histórica, e, assim, da necessidade da educação formal para a apropriação de conceitos e compreensão do real, já que a simplificação de tarefas torna mais complexa os instrumentos de produção e relação social e, portanto, exigem o desenvolvimento de competências cognitivas complexas.

\subsection{O ideário do ensino de Língua Portuguesa}

Considerar o sujeito como ser que se constitui na história, conforme a concepção de subjetividade discutida por Saviani (2003), é pensá-lo como ser inconcluso, incompleto. Admitir a noção de constitutividade é admitir, também, a noção de espaço para o sujeito, e a necessidade de um conjunto aberto de instrumentos para se operar o processo de constituição. É nesse sentido que Geraldi (2010) situa a educação como lugar de constituição do sujeito, por ser espaço de mediações, que permite a interação: "a leitura do mundo e a leitura da palavra são processos concomitantes na constituição dos sujeitos" (p. 32).

A educação como processo que permite mediações entre sujeitos implica admitir a escola como o lugar da subjetividade, do genérico humano para que o indivíduo se reconheça como pessoa, construa categorias para compreender o mundo e tenha a possibilidade de superar a realidade. Estudiosos observam que a educação apresenta dificuldades para desenvolver sua essência emancipatória, desenvolve-se pautada no 
pragmatismo, inserindo o educando ainda mais na realidade, priorizando o cotidiano, o imediatismo.

Ao se remeter às críticas quanto ao desenvolvimento da linguagem na escola, Geraldi (2010) observa o senso comum de que a linguagem é fundamental para o desenvolvimento intelectual de qualquer homem, para a "formação de conceitos que permitem aos sujeitos compreender o mundo e nele agir" (p. 34). Por isso destaca a importância de se pensar a educação considerando a linguagem como o princípio, que tem a interlocução como lugar privilegiado. Nesse processo de interlocução, exige-se instaurar no processo educacional a singularidade dos sujeitos, e considerar os discursos como cada vez mais únicos, densos em suas próprias condições de produção, que se fazem no tempo e constituem-se na história. Pensar a linguagem a partir do processo interativo significa admitir a historicidade da linguagem, em que acontecimentos passados construíram expressões, variedades, gêneros, estruturas sintáticas, por isso, nunca está pronta e acabada, mas em movimento, sempre em constituição; é admitir a constituição contínua de sujeitos, à medida que interagem com os outros; e admitir que o contexto das interlocuções é constitutivo dos discursos proferidos, que se tornam possiveis no interior e nos limites de uma determinada formação social, construindo novos limites.

Essas questões são abordadas por Geraldi (2010) para explicitar a questão da chamada "língua padrão" ou "língua culta", ressaltando que as diferenças na língua são resultado do trabalho coletivo, que não há fronteiras explícitas entre "linguagem popular" e "linguagem culta" porque a língua constitui-se dos inúmeros processos de interação e, portanto, é naturalmente variável. Não se trata de aprender língua padrão para se ter acesso à cidadania, mas de construir o novo, reelaborar a cultura, confrontando as diferentes posições, as diferentes formas linguísticas e enunciados, para alcançar o objetivo da educação, construir sujeitos, cidadãos participativos, autônomos, emancipados. 
Nos Parâmetros Curriculares Nacionais voltados para a Língua Portuguesa é explícito o principal objetivo da educação escolar, fazer com que os estudantes dominem conhecimentos que os façam crescer como cidadãos, plenamente reconhecidos e conscientes do seu papel social, o que inclui proporcionar-Ihes acesso tanto aos domínios tradicionalmente existentes no contexto escolar quanto aos contemporâneos.

Entre as questões relacionadas ao ideário do ensino de Língua Portuguesa na contemporaneidade, encontramos debates voltados para 0 desenvolvimento dos seguintes eixos/temas: leitura, oralidade, produção textual e conhecimentos linguísticos. As reflexões contemporâneas para o ensino de língua voltam-se para o desenvolvimento desses eixos/ temas a partir da inserção e/ou revisão dos seguintes conceitos/ conteúdos: alfabetização, leitura, gêneros textuais, letramento, gramática e variação linguística, sobre os quais apresentamos breves discussões de estudiosos da educação que buscam revisar esses conceitos, por vezes, considerados ainda confusos na prática de ensino.

Em meio a esse debate educacional, identificamos a variação linguística como um dos conceitos essenciais para o desenvolvimento da educação linguística que atenda às perspectivas de formação no mundo contemporâneo. O lugar da variação na educação linguística apresenta destaque, especialmente, a partir da publicação dos PCN que, considerando os avanços das pesquisas linguísticas sobre os fenômenos da língua, reconhece a diversidade linguística, cultural, social e política existente no país, trazem reflexões que apontam para a importância do tratamento da variação linguística no ensino de língua portuguesa e desenvolvem as diretrizes oficiais considerando o respeito à diversidade como principal eixo das propostas do documento, com objetivos de levar o aluno a conhecer e valorizar a pluralidade de manifestações linguísticas em sua totalidade,

Respeitar e preservar as diferentes manifestações da linguagem utilizadas por diferentes grupos sociais, em suas esferas de socialização; usufruir do patrimônio nacional e internacional, com 
suas diferentes visões de mundo; e construir categorias de diferenciação, apreciação e criação (BRASIL, 2000, p. 9).

O desenvolvimento de estudos voltados para as discussões sobre a relação entre variação linguística e ensino, assim como as reflexões desenvolvidas em torno dos conceitos/conteúdos de letramento, alfabetização, gêneros textuais, gramática, orientam a revisão das concepções tradicionais e, nesse sentido, surgem orientações de especialistas voltadas para a formação de cidadãos, considerando os avanços da ciência. Diante disso, verificamos, nos meios acadêmicos e pedagógicos, trabalhos que objetivam discutir sobre os avanços nos estudos linguísticos, situando a variação como um dos eixos do ensino de língua, com maior destaque a partir da década de 1960, e relacioná-la às práticas pedagógicas, contribuindo para a revisão das concepções e práticas de ensino de Língua Portuguesa.

\section{AS ORIENTAÇÕES LINGUÍSTICAS PARA A PRÁTICA DE ENSINO DE LÍNGUA PORTUGUESA}

A questão principal que norteia essa pesquisa é: Como a Linguística compreende considerar a variação no ensino de Língua Portuguesa? Se já existe resposta para este questionamento, ela parece ainda não ser assim tão clara, já que mesmo reconhecendo a língua como fenômeno variável ainda se verifica um tratamento inadequado para este fenômeno no ensino de Língua Portuguesa.

Com o objetivo de explicitar como a Linguística compreende a articulação da variação com o ensino, investigamos as pesquisas e orientações dos seguintes especialistas: Suassuna (1995), Bortoni-Ricardo (2004; 2014); Bortoni-Ricardo e Sousa (2014); Bagno (2002; 2007), Sousa e Machado (2014), Cardoso e Cobucci (2014), Martins e Moura (2014), Mattos e Silva (2004), Faraco (2008; 2015), Neves (2014), Martins et al (2014); Vieira e Freire (2014), Cyranka (2014), Pedrosa (2014), Lima (2014), Ziles e Faraco (2015), Vieira (2014), Brandão (2014), Lopes (2014). 
Os pesquisadores da ciência linguística, ao discutirem os atuais conceitos e pressupostos em torno da variação linguística, reconhecem a forte e imprescindível contribuição dos estudos da gramática para a compreensão da heterogeneidade constitutiva da língua. A Linguística, ao surgir como ciência da linguagem verbal humana, desencadeou um conjunto de pesquisas de vertentes teóricas que passaram a ter como foco a língua como um fato social, a princípio apresentando a sua realidade estrutural apenas em suas condições internas e, posteriormente, relacionada ao meio social, considerada como um conjunto de variedades que apresenta unidade, sistematicidade.

Apesar das críticas aos preceitos gramaticais, à descrição dos fenônemos linguísticos baseados na concepção de homogeneidade, para o desenvolvimento de seus estudos, a Linguística tem na tradição gramatical "ponto de partida" de suas reflexões e conceituações para o estudo atual da língua. Portanto, Linguística e Gramática Tradicional não são teorias em competição, mas em complemento, como declara Neves (2014) e como bem explicita Borges Neto (2013):

Os gramáticos gregos e latinos identificaram níveis de análise, como a oração e a palavra, desenvolveram noções teóricas, como sílaba, palavra, sujeito e predicado, flexão, nome e verbo etc., e estabeleceram relações entre essas noções. Apesar de adotarem padrões de exigência mais frouxos do que as teorias científicas atuais, realizaram um trabalho de teorização essencialmente igual ao que realizam os cientistas contemporâneos (p. 2).

Ressaltamos, ainda, nas pesquisas linguísticas, que o sistema de ensino é reflexo de toda a normatividade já existente na organização social, que impõe o certo e o errado, regras do bom uso, e dificulta a visão positiva para a variação inerente não só na língua.

As discussões indicam, também, que as terminologias que buscam denominar os fenônemos estudados refletem a realidade socioeconômica e cultural assentada em nossa sociedade, de um lado a população oriunda de zona rural, de baixa escolaridade, de outro a população urbana escolarizada. Apesar de ser evidente a mescla entre as variedades, o que 
implica considerar contínuos, a dicotomia ainda se apresenta de forma mais marcante tanto nos campos sociais quanto linguísticos.

Os pesquisadores da educação concordam que refletir sobre a língua é pensar em variação e mudança e defendem a reformulação dos modelos teóricos educacionais, destacando para a revisão dos eixos de ensino e a importância de compreender os conceitos relacionados ao estudo da língua.

Ao investigarmos as pesquisas linguísticas selecionadas, verificamos a principal orientação de que, no ensino de Língua Portuguesa, é imprescindível reconhecer a língua como um fenômeno heterogêneo, variável e sistematizável, desenvolver a reflexão para o ensino que divulgue a língua em reais situações e intenções de uso e promover o respeito para as diferentes variedades. Para refletir, reconhecer, respeitar, os linguistas propõem que o professor desenvolva atividades voltadas para o contato com os usos em situações comunicativas reais, tais como pesquisas por meio de entrevistas, filmagens, gravações, leituras, reescrita de textos, o que deve levar o aluno a verificar a diversidade existente de acordo com cada situação e função comunicativa, a reconhecer a existência de diferentes padrões na língua. $E$, então, ao professor cabe ensinar que há, entre esses diversos usos, regras eleitas socialmente como mais adequadas para contextos mais monitorados, o que a maioria dos estudiosos denomina de "norma culta", termo/conceito que ainda desencadeia dúvidas nas propostas pedagógicas e indica a necessidade de maiores reflexões.

Entre as propostas, observamos a orientação de que a escola deve divulgar a língua em sua heterogeneidade e ensinar a língua padrão, como afirma Suassuna (1995), visto que inserir a reflexão para a variação linguística não significa excluir a reflexão gramatical, mas ampliar o ensino de língua para discussões críticas quanto aos fenônemos gramaticais e oportunizar ao aluno o conhecimento de normas que irão the permitir participação social mais ativa. 
Temos em Bagno $(2002,2007)$ um pesquisador que mais polemiza os preceitos da gramática tradicional, a noção de língua homogênea ainda fortemente presente no ensino, na mídia e no senso comum. Por isso, defende o desenvolvimento de uma "Pedagogia da Variação Linguística" com o objetivo de divulgar as contribuições da ciência para o ensino. Para esse pesquisador, desenvolver a Pedagogia da Variação Linguística é promover o reconhecimento das diferentes variedades linguísticas por meio da pesquisa, elaboração de projetos que permitam investigar formas linguísticas em situações reais de uso, tais como filmagens, entrevistas, gravações, debates. Diante da conscientização para a diversidade, orienta, então que ao aluno seja oportunizado o domínio da variação mais prestigiada socialmente, o conhecimento das formas divulgadas pela tradição gramatical, além de evidenciar as consequências sociais dos usos variáveis. Dentre suas orientações, podemos destacar:

Garantir o acesso dos alunos e das alunas a outras formas de falar e de escrever, isto é, permitir que aprendam e aprendam variantes linguísticas diferentes das que eles/elas já dominam - isso significa ampliar o repertório comunicativo, ter à sua disposição um número maior de opções, que poderão ser empregadas de acordo com as necessidades da interação; [...] promover o conhecimento ativo das convenções dos muitos gêneros que circulam na sociedade, sobretudo dos gêneros escritos mais monitorados;

Promover o conhecimento da diversidade linguística como uma riqueza da nossa cultura, da nossa sociedade, ao lado de outras diversidades culturais [...] (BAGNO, 2007, p. 84-85).

Em vez de tentar ensinar somente a regra $A$ ou somente a regra $B$, como se elas fossem mutuamente excludentes, é possível transformar em objeto e objetivo de ensino a própria existência de $A$ e $B$, e o convívio das duas.

Não se trata, portanto, de substituir a forma nova pela antiga, nem a antiga pela nova, mas de compreender os mecanismos da variação e das mudanças linguísticas, construir uma atitude de simpatia frente às formas variantes, uma atitude de investigação e de observação da dinâmica da linguagem (BAGNO, 2007, p. 116).

Outros pesquisadores, também, orientam nesse mesmo sentido a variação para o ensino de língua portuguesa, como Bortoni-Ricardo (2004; 2014) Bortoni-Ricardo e Sousa (2014). Vimos nestes estudos a proposta de uma pedagogia culturalmente sensível, que significa conscientizar 0 aluno 
para todas as formas da língua efetivamente presentes na fala dos usuários, refletir sobre a variação como algo natural e desenvolver o ensino das variedades voltado para a noção da adequação ao contexto e conforme às expectativas dos falantes, o que implica ensinar ao aluno a norma eleita socialmente. Por isso, defende a abordagem dos fenônemos gramaticais conforme suas variações, comparando-os ao que temos registrados nas gramáticas sobre as formas dos usos:

Propomos um trabalho sobre fenômenos gramaticais que envolvem a linguagem em uso, com suas variações, na modalidade oral e escrita, fenômenos materializados em gêneros discursivos diversos, com a abordagem dos conhecimentos da gramática normativa e conhecimentos da sociolinguística, oriundos de pesquisas desenvolvidas há mais de trinta anos no Brasil, focalizando o "certo" ou "errado" ou inovações e variação (BORTONI-RICARDO; SOUSA, 2014 p. 14).

Cardoso e Cobucci (2014), Sousa e Machado (2014), Bortone e Alves (2014), Martins e Moura (2014) que compõem obra organizada por Bortoni Ricardo, explicitam orientações condizentes às propostas de Bortoni-Ricardo e Marcos Bagno quando, ao discutirem fenônemos gramaticais, como "concordância nominal", "coesão referencial", "hipercorreção", concordam que o ensino de língua deve ser conduzido baseado em textos autênticos, em situações comunicativas reais a partir do qual se deve orientar para o conhecimento das normas mais monitoradas, comparar os fenônemos gramaticais observados nos diferentes contextos sociais com as descrições gramaticais, levando o aluno a ampliar sua competência comunicativa, sem deixar de conscientizá-lo para os valores atribuídos aos usos, os quais demonstram que, apesar das variedades identificadas serem legítimas, não apresentam a mesma aceitação social.

Destacamos, também, a orientação de que a escola deve considerar os alunos como senhores de sua língua, partir do uso efetivo deles para o conhecimento de todas as outras possibilidades o que deve ocorrer por meio do desenvolvimento do interesse pela leitura que permitirá ao aluno aumentar seu arcabouço teórico sobre a língua. Nesse sentido Mattos e Silva 
(2004) considera não ser necessário tratar de julgamento desvalorativo, mas trabalhar com a valoração da diversidade e torná-lo capaz de se adequar às diversas circunstâncias:

O julgamento desvalorativo do uso do aluno não entraria no processo. A valorização da diversidade deve ser trabalhada e adequadamente valorizada e o objetivo final a atingir-se será tornar o estudante pluridialetal - no seu dialeto familiar, no dialeto do seu grupo social, consciente da variação possível em outros grupos sociais, e senhor também das normas do dialeto socialmente privilegiado (MATTOS e SILVA, 2004, p. 76).

Constatamos que sobre a variação no ensino de língua esta pesquisadora é clara ao defender que haja a reflexão em torno de todas as variedades, para que, então, seja ensinada ao aluno a forma culta esperada pela sociedade, o que podemos confirmar no seguinte trecho no qual fala sobre os "ajustes" que a sociedade exige:

Tais ajustes, esperados pela sociedade, poderão ser feitos sem a pretensão de estar-se ensinando gramática, no primeiro sentido aqui definido, mas apenas treinando uma fala/escrita em diversos contextos de comunicação, de acordo com os objetivos da escola e consequentemente com o padrão de uso que ela busca transmitir. Nessa etapa da aprendizagem escolar, sem pretensão de uma suposta sistematização, desenvolver-se-ia um treinamento que comparasse os usos efetivos dos estudantes aos outros usos do padrão institucionalmente requerido (MATTOS e SILVA, 2004, p. 81-82).

Faraco $(2008,2015)$ também se destaca entre os pesquisadores que objetivam avançar na "Pedagogia da Variação Linguística", com orientações para 0 ensino que tenha como ponto de partida 0 reconhecimento da heterogeneidade linguística para o ensino da norma recorrente nos meios sociais mais monitorados. Por isso, Faraco argumenta sobre a necessidade de se explicitar a norma culta atual para embasamento pedagógico, divulgar as atuais concepções e resultados de descrições linguísticas, e ainda ampliar a discussão para além das aulas de Língua Portuguesa.

Neves (2010) compartilha das contribuições dos demais linguistas e destaca-se por orientar que, no estudo de gramática a norma-padrão é 
mais uma das variedades da língua e que a função da escola para reconhecer a variação como princípio e ensinar a língua padrão é vivenciar a língua em sua plenitude: falar, ler, escrever, sendo assim, propiciar reflexões para que o falante compreenda a funcionalidade das escolhas que faz. Neves orienta que não deve ser foco da escola avaliar usos linguísticos conforme os julgamentos sociais, mas assegurar ao aluno a autonomia no uso da linguagem, a compreensão da naturalidade da existência de norma e possibilidades de escolha. Para tanto, o ensino deve considerar a observação da efetiva produção linguística e conduzi-lo a conhecer a norma prestigiada:

\begin{abstract}
A única certeza é a de que temos de ir da língua - da linguagem para o padrão (isto é, do uso para a norma) e não do padrão para a linguagem e para a língua, que é o que numa visão acrítica se tem feito. Pode-se esperar que uma gramática de usos opere nesse sentido, já que parece aceitável a premissa de que é o exame dos usos (variados) que pode referendar a instituição de padrões (NEVES, 2014, p. 22).
\end{abstract}

Martins et al (2014), Pedrosa (2014), Vieira e Freire (2014), Lima (2014) e Cyranka (2014) destacam-se entre os pesquisadores da Linguística por apresentarem o panorama das variedades do português brasileiro, associando-as a propostas para o trabalho docente que levem para a sala de aula essas descrições e desenvolvam o tratamento adequado da variação linguística. Ressalta-se a orientação desses pesquisadores para a importância do domínio sociolinguístico do professor quanto às variedades realizadas tanto na produção oral quanto escrita de seus alunos, além de ter domínio dos conceitos e princípios em torno dos fenônemos para que a revisão nas práticas sejam bem sucedidas.

Ao professor, cabe, no papel que Ihe foi confiado: (i) dar orientações seguras nas atividades de produção textual valendo-se das preferências pautadas nas efetivas normas de uso brasileiras faladas e escritas; (ii) promover, nas atividades de leitura e de escrita dos mais diversos gêneros, o reconhecimento de usos linguísticos pouco familiares à comunidade de fala a que pertencem seus alunos, por serem esses usos pertencentes a outras variedades, prestigiadas ou não, ou, ainda, a outras sincronias (MARTINS et al, 2014, p. 13). 
A descrição desses fenômenos permitirá ao professor traçar um continuum de variação do que idealmente se concebe como norma culta a ser ensinada, sendo esta também heterogênea como qualquer variedade linguística. Entende-se que, dessa forma, a sociolinguística cumpre parte do papel que the cabe na (in)formação dos professores no que se refere ao trabalho pedagógico com a variação linguística (VIEIRA; FREIRE, 2014, p. 84, grifos dos autores).

Nos livros/materiais/manuais didáticos, não há necessidade de se justificar temas como sintaxe, texto, leitura etc., no entanto, parece que precisamos fazê-lo quanto à variação linguística. E isso faz com que esse tema seja visto como mais um conteúdo que deva ter seu próprio capítulo, quando já sabemos que a variação linguística deve estar inserida no ensino dos temas referidos anteriormente (LIMA, 2014, p. 117).

É consenso que a competência dos alunos em leitura e escrita deve partir do (re)conhecimento da pluralidade de normas existentes e da existência de uma norma culta plural efetivamente praticada nos meios mais monitorados, conforme descrevem os sociolinguistas, seja no sistema pronominal, na representação de sujeito e objeto, no uso de conectores, no sistema fonético-fonológico, para conduzir o aluno ao domínio dos usos de acordo com os gêneros e as situações comunicativas para os quais devem estar preparados.

Os pesquisadores ressaltam que a maior dificuldade está na formação docente que ainda se apresenta pouco preparada para lidar com o ensino numa perspectiva variacionista, além de que há a necessidade de maior divulgação - ou divulgação mais adequada - das descrições das variedades nos meios didáticos.

Apesar dos inúmeros desafios para um ensino condizente com o real funcionamento da língua, os pesquisadores apresentam orientações significantes para mudanças na prática pedagógica, para pensar a variação no ensino de Língua Portuguesa e refletir sobre as descrições dos fenômenos linguísticos efetivamente observáveis que podem embasar a prática pedagógica do professor. Os pesquisadores explicam que o reconhecimento da língua como fenômeno variável deve ocorrer pelo contato, observação e pesquisa, no espaço escolar e social, de textos 
autênticos em situações comunicativas reais para a conscientização da diversidade, para orientá-los sobre os usos que vão Ihes permitir participar dos contextos em que estiver inserido.

Como o ensino reflete a normatividade presente nas diversas áreas sociais, as atuais discussões linguísticas voltadas para a heterogeneidade, a noção de variação como naturalmente presente na língua ainda não são bem acolhidas no meio escolar e social. Por isso, além desses estudos que orientam para o real funcionamento da língua e, então, para novas práticas pedagógicas é preciso revisar a formação docente que demonstra apresentar-se deficiente por não acompanhar os avanços das pesquisas linguistas, e segundo Faraco $(2008 ; 2015)$, encontrar meios para que essas reflexões ultrapassem os bancos escolares e acadêmicos, que instaure um efetivo debate nacional sobre nossas questões linguísticas que defendem a importância de se pensar a variação para o ensino.

\section{CONSIDERAÇÕES FINAIS}

Retomando o objetivo desta pesquisa que consistiu em investigar como a Linguística compreende a articulação entre variação e ensino de língua, observamos um consenso entre os pesquisadores nas orientações que possibilitem ao aluno o reconhecimento da constituição histórica da sua língua desde os registros tradicionais aos mais contemporâneos, numa direção positiva, levando-o a compreender, por meio do contato direto com textos autênticos (entrevistas, gravações, textos que circulam em diversos meios), a língua como sinônimo de variação que se constitui por diferentes normas, que podem ser usadas de acordo com a situação comunicativa, com o interlocutor e a função que se quer desenvolver.

O recorte das obras analisadas ocorreu a partir da pesquisa e seleção de textos eletrônicos - artigos, ensaios, dissertações - que nos possibilitaram formar um corpus constituído por capítulos de livros, fontes primárias das pesquisas eletrônicas. Os principais critérios permitiram selecionarmos pesquisas de mestres e doutores na área de linguística e educação, com 
publicações em fontes qualificadas que apresentam como principal objetivo refletir e orientar sobre os avanços da pesquisa linguística para o ensino de Língua Portuguesa.

O debate sobre a variação linguística como conceito a ser inserido no ensino de Língua Portuguesa faz parte do debate geral da educação para o qual se define como objetivo principal formar indivíduos que superem o pragmatismo, o imediatismo e se tornem indivíduos críticos, autônomos para o desenvolvimento de uma sociedade verdadeiramente democrática. Nesse sentido, os pesquisadores da língua propõem pensar sobre a língua como um dos meios para que o indivíduo seja capaz de agir no mundo, para isso, defendem a importância de se revisar os conceitos e pressupostos em torno do ensino de língua de modo que se ampliem os conhecimentos linguísticos para além dos preceitos da gramática tradicional, ainda, predominante no ensino.

As discussões para o ensino implicam desenvolver a concepção heterogênea de língua que considere o sujeito como ser que é constituído historicamente ao mesmo tempo em que constitui a história. Oportunizar o reconhecimento da língua em sua diversidade, dando-lhes oportunidades de conhecer e dominar os usos que os possibilitem participar de qualquer esfera social faz parte do ideário de educação em desenvolver a atuação na sociedade como sujeitos emancipados. Discutir e orientar sobre a importância de se repensar os conceitos de ensino de língua portuguesa em torno dos principais eixos, leitura, escrita, oralidade, e compreensão de normas que regem a língua, sugere desenvolver a totalidade de capacidades linguísticas do indivíduo, fator principal para a superação da exploração capitalista que tem as relações de dominação, divisão de classes e desigualdades como principais características.

As reflexões e orientações linguísticas parecem tratar-se de discussões que vão de encontro à concepção de educação ominilateral, conforme discutimos na segunda seção, que possibilite ao educando conhecer e refletir sobre como a linguagem se constitui, sobre as possibilidades de usos, 
que compreenda a linguagem como expressão de identidades, da história em que se desenvolveu, visto ser o homem sujeito que se faz na história.

Entretanto, ao se defender o desenvolvimento do sujeito emancipado, verificarmos nos discursos dos pesquisadores a afirmação de que o principal objetivo de ensino é o domínio da "norma culta" e/ ou "norma padrão" - os principais termos identificados nos debates em torno da compreensão e descrição do funcionamento linguístico - que induz a compreender ainda o peso das exigências sociais capitalistas sobre a formação escolar e a adequação à dominação da sociedade capitalista. Nesse sentido, observamos ainda a necessidade de se avançar na compreensão das concepções de língua para que se alcance o objetivo em ampliar a reflexão sobre a língua portuguesa para o genérico humano, para que 0 acesso à escrita amplie os conhecimentos dos alunos para que se tornem conscientes de suas escolhas, de seus papéis sociais para crescer na história.

Entre os avanços e desafios a serem enfrentados, tanto nos estudos linguísticos quanto nas concepções e práticas de ensino, podemos inferir, nas investigações que fizemos das pesquisas linguísticas selecionadas, que articular variação e ensino é compreender que língua é variação, é compreender como princípio o respeito às variedades, à diversidade, o combate ao preconceito, para orientar o ensino dos padrões de escrita existentes na língua sem, porém, focalizar apenas uma norma, julgando-a como correta em oposição às demais, já que o preconceito linguístico apenas reforça o estigma social e a exploração capitalista sobre as pessoas de menor poder aquisitivo.

Nesse sentido, é levar o aluno a conhecer as formas de organização da língua em sua complexidade, possibilitá-lo a aprendizagem crescente dos domínios dos padrões da escrita, dos usos mais monitorados da língua, torná-lo sujeito que compreende a língua em sua história e o compreende como sujeito que pode transformá-la por meio de seus conhecimentos.

Este estudo permite sugerir o desenvolvimento de outras questões de estudo: uma delas refere-se à investigação do surgimento dos conceitos de 
norma culta, norma padrão e gramática tradicional na história da gramática escolar; outra questão refere-se à compreensão do ensino de norma culta e norma padrão. São conceitos que, conforme verificamos, ainda não são bem esclarecidos tanto no meio escolar quanto nas pesquisas linguísticas, e novos estudos em torno dessa temática podem contribuir tanto com este estudo, quanto com os objetivos de ensino e com a formação de professores.

\section{REFERÊNCIAS}

ABRANTES A.; MARTINS, L. M. A produção do conhecimento científico: relação sujeito-objeto e desenvolvimento do pensamento. Interface Comunic, Saúde, Educ, v.11, n.22, p.313-25, mai/ago, 2007. Disponível em: <http://www.scielo.br/pdf/icse/v1 ln22/10.pdf>. Acesso em 08 de março de 2016

ADORNO, T. W. Educação e emancipação. 2. ed. Tradução de Wolfgang Leo Maar. Rio de Janeiro: Paz e Terra, 2000. Disponível em < http://www.verlaine.pro.br/txt/pp5/adorno-educacao.pdf>. Acesso em 03 de março de 2016.

AGOSTINHO, S.R.N.; COELHO, I.L. Concordância de primeira pessoa do plural na escrita escolar. In: ZILLES, A. M. S.; FARACO, C. A. et al. (orgs.). Pedagogia da variação linguística: língua, diversidade e ensino. São Paulo: Parábola Editorial, 2015.

BAGNO, M. Língua materna: letramento, variação e ensino/ Marcos Bagno, Gilles Gagné, Michael Stubbs. São Paulo: Parábola, 2002.

BAGNO, M. Nada na língua é por acaso: por uma pedagogia da variação linguística. São Paulo: Parábola, 2007.

BARBOSA, A. G. Saberes gramaticais na escola. In: VIEIRA, S. R.; BRANDÃO, S. F. (orgs.). Ensino de gramática: descrição e uso. $2^{a}$ ed., São Paulo: Contexto, 2014.

BORTONE, M. E.; ALVES, S. B. O fenômeno da hipercorreção. In: BORTONIRICARDO, S. M. et al. (orgs.). Por que a escola não ensina gramática assim? São Paulo: Parábola, 2014.

BORTONI-RICARDO, S. M. Educação em língua materna: a sociolinguística em sala de aula. São Paulo: Parábola, 2004.

BORTONI-RICARDO, S. M. Manual de Sociolinguística. São Paulo: Contexto, 2014.

BORTONI-RICARDO, S. M.; SOUSA, R. M. de. Introdução. In: BORTONIRICARDO, S. M. et. al. (orgs.). Por que a escola não ensina gramática assim? São Paulo: Parábola, 2014. 
BRANDÃO, SILVIA F. Concordância nominal. In: VIEIRA, S. R.; BRANDÃO, S. F. (orgs.). Ensino de gramática: descrição e uso. $2^{a}$ ed., São Paulo: Contexto, 2014.

BRASIL. Secretaria de Educação Fundamental. Parâmetros Curriculares Nacionais: língua portuguesa/Secretaria de Educação Fundamental. Brasilia, 1997.

BRASIL. Parâmetros Curriculares Nacionais: terceiro e quarto ciclos do ensino fundamental: língua portuguesa/Secretaria de Educação Fundamental. Brasília: MEC, 1998.

BRASIL. Parâmetros Curriculares Nacionais: Ensino médio: língua portuguesa/Secretaria de Educação Fundamental. Brasília: MEC, 2000.

CALLOU, D. Gramática, variação e normas. In: VIEIRA, S. R.; BRANDÃO, S. F. (orgs.). Ensino de gramática: descrição e uso. $2^{a}$ ed., São Paulo: Contexto, 2014.

CARDOSO, C. R.; COBUCCl, P. Concordância de número no português brasileiro. IN: BORTONI-RICARDO, S. M. et al. (orgs.). Por que a escola não ensina gramática assim? São Paulo: Parábola, 2014.

CYRANKA, L. Avaliação das variantes: atitudes e crenças em sala de aula. In: MARTINS, M. A.; VIEIRA, S. R.; TAVARES, M. A. (orgs.). Ensino de português e sociolinguística. São Paulo: Contexto, 2014.

DUARTE, N. A contradição entre universalidade da cultura humana e o esvaziamento das relações sociais: por uma educação que supere a falsa escolha entre etnocentrismo ou relativismo cultural. Educação e Pesquisa, São Paulo, v.32, n.3, p. 607-618, set./dez. 2006. Disponível em < http://www.revistas.usp.br/ep/article/view/28029>. Acesso em 23 de janeiro de 2016.

FARACO, C. A. Norma Culta Brasileira: desatando alguns nós. São Paulo, Parábola, 2008.

FARACO, C. A. Desde quando somos normativos. In: VALENTE, A. C. (org.). Unidade e variação na língua portuguesa: suas representações. São Paulo: Parábola, 2015.

FARACO, C. A. Norma culta brasileira: construção e ensino. IN: ZILLES, A. M. S.; FARACO, C. A. et al. (orgs.). Pedagogia da variação linguística: língua, diversidade e ensino. São Paulo: Parábola Editorial, 2015.

FREITAS, V. A. L.; SOUSA, M. A. F. Verbos impessoais: variação no uso de haver, ter e fazer. In: BORTONI-RICARDO, S. M. et al. (orgs.). Por que a escola não ensina gramática assim? São Paulo: Parábola, 2014.

FRIGOTTO, G. Fundamentos científicos e técnicos da relação trabalho e educação no Brasil de hoje. In: LIMA, J. F.; NEVES, L. W. (orgs.). Fundamentos da educação escolar do Brasil contemporâneo. Rio de Janeiro: Fiocruz, 2006. p.

241-288.

Disponível

em 
<http://www.fiocruz.br/editora/cgi/cgilua.exe/sys/start.htm? infoid=412\&sid=5 >. Acesso em 08 de março de 2016.

GERALDI, J. W. A aula como acontecimento. São Carlos: Pedro \& João Editores, 2010.

GERALDI, J. W. Alfabetização e letramento: perguntas de um alfabetizado que lê. Texto apresentado em sessão especial da Anped, 2010b. Disponível em

http://www.antigomoodle.ufba.br/file.php/10203/Textos/Letramento_e_Alfab etizacao_geraldi.pdf>. Acesso em 27 de janeiro de 2016.

GERALDI, J. W. Ler e escrever: uma mera exigência escolar. Conferencia. Universidade Federal do Triangulo Mineiro, 2007. Disponível em < http://seer.uftm.edu.br/revistaeletronica/index.php/sell/article/download/2 0/27>. Acesso em 06 de outubro de 2016

GONZÁLEZ, C. A. Variação linguistica em livros de português para o EM. IN: ZILLES, A. M. S.; FARACO, C. A. et al. (orgs.). Pedagogia da variação linguística: língua, diversidade e ensino. São Paulo: Parábola Editorial, 2015.

HELLLER, A. Estrutura da vida cotidiana. In: HELLLER, A. O cotidiano e a História. Editora Paz e Terra. São Paulo, 2004, p. 17-41.

LIMA, R. J. Variação Linguística e os livros didáticos de Português. In: MARTINS, M. A.; VIEIRA, S. R.; TAVARES, M. A. (orgs.). Ensino de português e sociolinguística. São Paulo: Contexto, 2014.

LOPES, C. R. Pronomes Pessoais. In: VIEIRA, S. R.; BRANDÃO, S. F. (orgs.). Ensino de gramática: descrição e uso. $2^{a}$ ed., São Paulo: Contexto, 2014.

MARTINS, M. A. et al. Contribuições da Sociolinguística Brasileira para o ensino de Português. In: MARTINS, M. A.; VIEIRA, S. R.; TAVARES, M. A. (orgs.). Ensino de português e sociolinguística. São Paulo: Contexto, 2014.

MARTINS, L. R.; MOURA, A. V. de. Orações relativas e interrogativas: aproximação entre teoria e prática na sala de aula. In: BORTONI-RICARDO, S. M. et al. (orgs.). Por que a escola não ensina gramática assim? São Paulo: Parábola, 2014.

MATTOS E SILVA, R. V. O português são dois: novas fronteiras, velhos problemas. São Paulo: Parábola Editorial, 2004.

NEVES, M. H. de M. Que gramática estudar na escola? 4. ed. São Paulo: Contexto, 2014.

PEDROSA, J. L. Variação Fonético-fonológica e ensino de português. In: MARTINS, M. A.; VIEIRA, S. R.; TAVARES, M. A. (orgs.). Ensino de português e sociolinguística. São Paulo: Contexto, 2014.

SAVIANI, D.; DUARTE, N. A formação humana na perspectiva históricoontológica. Revista Brasileira de Educação, v. 15 n. 45 set./dez. 2010. Disponível em < http://www.scielo.br/pdf/rbedu/v15n45/02>. Acesso em 26 de janeiro de 2016. 
SAVIANI, D.; DUARTE, N. Perspectiva marxiana do problema subjetividadeintersubjetividade. Conferência proferida no I Seminário Internacional sobre Filosofia e Educação. Passo Fundo, 29/09/2003. Disponível em < http://www.escolapcdob.org.br/file.php/1/materiais/pagina_inicial/Bibliotec a/76_SAVIANI_Dermeval_-

_Perspectiva_marxiana_do_problema_da_subjetividade-

intersubjetividade.pdf>. Acesso em 25 de agosto de 2016.

SIMÕES, L.J.; SOARES, S.M. Concordância nominal na fala infantil: implicações para a escola. In: ZILLES, A. M. S.; FARACO, C. A. et al. (orgs.). Pedagogia da variação linguística: língua, diversidade e ensino. São Paulo: Parábola Editorial, 2015.

SOUSA, R. M. de; MACHADO, V. R. Coesão Referencial: aspectos morfossintáticos e semânticos. In: BORTONI-RICARDO, S. M. et al. (orgs.). Por que a escola não ensina gramática assim? São Paulo: Parábola, 2014.

SUASSUNA, L. Ensino de Língua Portuguesa: uma abordagem pragmática. Campinas: Papirus, 1995.

VIEIRA, S. R. Colocação Pronominal. In: VIEIRA, S. R.; BRANDÃO, S. F. (orgs.). Ensino de gramática: descrição e uso. $2^{a}$ ed., São Paulo: Contexto, 2014.

VIEIRA, S. R. Concordância verbal. In: VIEIRA, S. R.; BRANDÃO, S. F. (orgs.). Ensino de gramática: descrição e uso. $2^{a}$ ed., São Paulo: Contexto, 2014.

VIEIRA, S. R.; FREIRE, G. C. Variação morfossintática e ensino de português. In: MARTINS, M. A.; VIEIRA, S. R.; TAVARES, M. A. (orgs.). Ensino de português e sociolinguística. São Paulo: Contexto, 2014.

Recebido em: Julho de 2017 Aprovado em: Dezembro de 2017 